\section{(6) OPEN ACCESS}

\title{
Vonoprazan prevents ulcer recurrence during long-term NSAID therapy: randomised, lansoprazole-controlled non-inferiority and single-blind extension study
}

\author{
Yuji Mizokami, ${ }^{1}$ Kazunori Oda, ${ }^{2}$ Nobuo Funao, ${ }^{2}$ Akira Nishimura, ${ }^{2}$ Satoshi Soen, ${ }^{3}$ \\ Takashi Kawai, ${ }^{4}$ Kiyoshi Ashida, ${ }^{5}$ Kentaro Sugano ${ }^{6}$
}

- Additional material is published online only. To view please visit the journal online (http://dx.doi.org/10.1136/ gutjnl-2017-314010).

${ }^{1}$ Endoscopic Center, University of Tsukuba Hospital, Tsukuba, Japan

${ }^{2}$ Takeda Development Center, Takeda Pharmaceutical Company Ltd, Osaka, Japan ${ }^{3}$ Department of Orthopaedic Surgery and Rheumatology, Kindai University Nara Hospital, Ikoma, Japan

${ }^{4}$ Endoscopy Center, Tokyo Medical University Hospital,

Tokyo, Japan

${ }^{5}$ Department of

Gastroenterology, Rakuwakai Otowa Hospital, Kyoto, Japan ${ }^{6}$ Department of Medicine, Jichi Medical University, Tochigi, Japan

Correspondence to Professor Yuji Mizokami, Endoscopic Center, University of Tsukuba Hospital, Tsukuba, Ibaraki 305-8576, Japan; yujimizokami@md.tsukuba.ac.jp

Received 20 February 2017 Revised 8 September 2017 Accepted 8 September 2017 Published Online First 7 October 2017

\section{PLinked}

- http://dx.doi.org/10.1136/ gutjnl-2017-315252

Check for updates

To cite: Mizokami Y, Oda K, Funao N, et al. Gut

2018:67:1042-1051.

\section{ABSTRACT}

Objective To assess the non-inferiority of vonoprazan to lansoprazole for secondary prevention of non-steroidal anti-inflammatory drug (NSAID)-induced peptic ulcer (PU) and the safety of vonoprazan during extended use. Design A phase 3, 24-week, multicenter, randomised, double-blind (DB), active-controlled study, followed by a phase $3, \geq 28$ week, multicenter, single-blind, parallelgroup extension study (EXT) in outpatients $(n=642)$ receiving long-term NSAID therapy who are at risk of PU recurrence. The patients received vonoprazan $(10 \mathrm{mg}$ or $20 \mathrm{mg}$ ) or lansoprazole $15 \mathrm{mg}$ once daily. For DB, noninferiority of the proportion of patients with recurrent PU within 24 weeks was analysed by Farrington and Manning test (significance level 2.5\%, non-inferiority margin 8.3\%; primary endpoint), recurrent PU within 12 weeks, bleeding and time-to-event of PU (secondary endpoint) and treatment-emergent adverse events (TEAEs). For EXT, TEAEs (primary endpoint), recurrent PU and safety (secondary) were assessed up to 104 weeks for patients in the extension study.

Results The non-inferiority of vonoprazan $10 \mathrm{mg}$ and $20 \mathrm{mg}$ to lansoprazole $15 \mathrm{mg}$ was verified (percentage difference $-2.2 \%, 95 \% \mathrm{Cl}-6.2 \%$ to $1.8 \%, \mathrm{p}<0.001$; $-2.1 \%, 95 \% \mathrm{Cl}-6.1 \%$ to $2.0 \%, \mathrm{p}<0.001$, respectively). The proportion of patients with endoscopically confirmed recurrent PU within 24 weeks was 3.3\%, 3.4\% and $5.5 \%$, for vonoprazan $10 \mathrm{mg}, 20 \mathrm{mg}$ and lansoprazole $15 \mathrm{mg}$, respectively. No significant safety concerns were identified.

Conclusion The non-inferiority of vonoprazan (10 and $20 \mathrm{mg}$ ) was verified in patients receiving long-term NSAIDs in DB; it was effective and well tolerated in EXT for longer than 1 year, with a safety profile similar to lansoprazole (15 mg).

Trial registration numbers NCT01452750, NCT01456260; Results.

\section{INTRODUCTION}

Non-steroidal anti-inflammatory drugs (NSAIDs) are commonly used to manage pain or inflammatory symptoms in conditions such as rheumatoid arthritis and osteoarthritis, but they can cause GI mucosal injury. ${ }^{1}$ In Japan, the prevalence of upper GI tract lesions in patients receiving NSAIDs has been reported to be as high as $62 \%$, with $>17 \%$

\section{Significance of this study}

What is already known on this subject?

- Non-steroidal anti-inflammatory drugs (NSAIDs) are commonly used as first-line analgesic agents, despite the risk of causing severe $\mathrm{Gl}$ adverse events, such as $\mathrm{Gl}$ bleeding. The prevalence of upper $\mathrm{Gl}$ tract lesions in patients receiving NSAIDs is very high and $>17 \%$ of lesions are confirmed as gastric or duodenal (peptic) ulcers.

- Proton pump inhibitors (PPIs) are recommended as a prevention of NSAID-related upper GI adverse events. However, as PPIs are not completely effective, better drugs for the prevention of these events are eagerly anticipated.

- Vonoprazan competes with potassium to inhibit $\mathrm{H}^{+}, \mathrm{K}^{+}$-ATPase; it does not require acid-induced activation, therefore vonoprazan demonstrated more potent and more sustained suppression of gastric acid secretion than lansoprazole in the preclinical studies.

What are the new findings?

- Vonoprazan (10 mg and $20 \mathrm{mg}$ ) was effective and well tolerated for prevention of NSAID-related peptic ulcer recurrence, and its efficacy level was equivalent to that of lansoprazole in at-risk patients.

- The safety profile of vonoprazan $(10 \mathrm{mg}$ and $20 \mathrm{mg}$ ) during long-term use was similar to that of lansoprazole $15 \mathrm{mg}$, and no new safety issue was identified.

- Daily vonoprazan dose of $10 \mathrm{mg}$ can be considered as the recommended clinical dose for prevention of NSAID-related peptic ulcer recurrence in at-risk patients.

How might it impact on clinical practice in the foreseeable future?

- Vonoprazan has the possibility to become a new treatment option for the prevention of NSAIDrelated $\mathrm{Gl}$ adverse events in high-risk patients.

of lesions confirmed as gastric or duodenal (peptic) ulcers. ${ }^{2}$ Despite the presence of lesions, $40 \%$ of patients may be asymptomatic ${ }^{2}$; however, GI symptoms do not predict the presence of mucosal injury. ${ }^{34}$ 
Current guidelines recommend that the first step for patients with NSAID-induced ulcers is discontinuation of NSAIDs ${ }^{5}$; however, such a strategy is not always feasible as arthritic pain may recur and negatively impact quality of life. ${ }^{6}$ Continuing NSAID therapy while preventing peptic ulcers is thus considered clinically important for the management of musculoskeletal pain. $^{7}$

The efficacy of proton pump inhibitors (PPIs), double-doses of histamine-2 receptor antagonists (H2RAs) and prostaglandin analogues (misoprostol) for primary and secondary prevention of NSAID-induced ulcers has been demonstrated in some studies and PPIs are currently widely used as first-line drugs. ${ }^{78}$ In Japan, lansoprazole at a dose of $15 \mathrm{mg}$ was approved for the first time in 2010 for the prevention of recurrence of peptic ulcer during NSAID administration. However, as it has been reported that up to $13 \%$ of patients treated with lansoprazole still experience ulcer recurrence, ${ }^{9}$ alternative secondary prevention treatment options continue to be sought. ${ }^{10}$ An earlier study has reported the efficacy of cyclo-oxygenase-2 (COX-2) inhibitors (celecoxib) and PPIs (esomeprazole) for patients at very high risk for recurrent ulcer bleeding. ${ }^{11}$

Vonoprazan, a potassium-competitive acid blocker (P-CAB), inhibits $\mathrm{H}^{+}, \mathrm{K}^{+}$-ATPase at the final stage of the acid secretory pathway in gastric parietal cells. ${ }^{10} 12$ Unlike PPIs, vonoprazan competes with potassium to inhibit the $\mathrm{H}^{+}, \mathrm{K}^{+}$-ATPase and also does not require acid-induced activation. ${ }^{13} 14$ While PPIs typically require approximately $3-5$ days to exert a maximal effect on gastric acid secretion, ${ }^{15}$ P-CABs produce strong and long-lasting inhibitory activity from the first dose. ${ }^{16}$ Results from a drug-drug interaction study showed that the pharmacokinetics of vonoprazan and NSAIDs (loxoprofen sodium, diclofenac sodium, meloxicam) were not affected during concomitant administration of repeated doses. ${ }^{17}$ The similar efficacy of vonoprazan and lansoprazole for the healing of gastric and duodenal ulcers has been demonstrated in a randomised clinical trial in patients with gastric and duodenal ulcers. $^{18}$

The aim of the current studies was to evaluate the non-inferiority of vonoprazan to lansoprazole for secondary prevention of peptic ulcers in patients requiring NSAID therapy for pain management and to evaluate the safety and tolerability of vonoprazan during extended use.

\section{MATERIALS AND METHODS Trial design}

Double-blind, multicenter, randomised, parallel-group, phase 3 study conducted in Japan to evaluate the non-inferiority of vonoprazan to lansoprazole in preventing occurrence of secondary ulcers in patients with a history of endoscopically confirmed gastric or duodenal ulcer (peptic ulcer) who require long-term NSAID therapy. Patients were randomised to receive study drug for a period of 24 weeks (figure 1A; figure 1 in the online supplementary file 1).

Endoscopic evaluations were conducted at weeks 12 and 24. Adverse events (AEs), physical examinations, medication compliance, vital signs and tests (clinical laboratory, pregnancy, serum gastrin (reference value of $37-172 \mathrm{pg} / \mathrm{mL}$ ) and pepsinogen I and II by RIA/PEG method) were performed at weeks 4, 8, 12, 16, 20 and 24.

\section{Single-blind extension study}

Subjects who completed the non-inferiority study were eligible for enrolment in the phase 3, multicenter, single-blind, parallel-group extension study to evaluate safety and ulcer recurrence during longer-term exposure. Patients were enrolled into the extension study on the day following the final visit of the preceding study and were required to complete a minimum of 28 weeks of follow-up up to a maximum of 80 weeks follow-up (figure $1 \mathrm{~B}$; figure 1 in the online supplementary file 1 ).

Using times from starting the double-blind study, endoscopy was performed at weeks 52, 76 and 104, and laboratory tests (clinical laboratory, pregnancy, serum gastrin and pepsinogen I and II) were performed at weeks 36, 52, 64, 76, 88 and 104. AEs, vital signs and physical examinations were performed every 4 weeks starting from week 28 to the end of participation in the study.

\section{Participants}

Subjects were enrolled in the double-blind study if they met the following criteria: male or female outpatients aged $\geq 20$ years with a history of peptic ulcer (documented endoscopically confirmed ulcer and/or endoscopically confirmed ulcer scars within 9 days before randomisation) who required continuous long-term therapy with NSAIDs during the treatment period for pain control related to a chronic disease (eg, rheumatoid arthritis, osteoarthritis). Adequate contraception for women of childbearing potential was required from the time of signing informed consent up to 4 weeks after the final dose. The eligibility of history of active ulcer or the presence of ulcer scar (defined as regenerative mucosa, fold convergence, wall deformation) at baseline endoscopy was determined by the Central Evaluation Committee consisting of two board-certified endoscopists (YM and KA). The Committee made an atlas of endoscopic images and held three educational investigator meetings for the standardisation.

Subjects were excluded if they had: endoscopically confirmed active ulcers or bleeding in the stomach or duodenum; intestinal or GI bleeding of unknown aetiology; scheduled operation or history of surgery affecting gastric acid secretion (eg, previous resection of the upper GI tract, vagotomy); history of gastric acid hypersecretion disorders (eg, Zollinger-Ellison syndrome); history of aspirin-induced asthma; history of hypersensitivity to vonoprazan, NSAIDs, or PPIs; illicit drug or alcohol abuse within the previous year; pregnancy, lactation, or intention to become pregnant or donate ova; any serious neurological, cardiovascular, pulmonary, hepatic, renal, metabolic, GI, urological, endocrinological or haematological disorders; history of malignancy within 5 years prior to screening; abnormal laboratory test values on the day of screening (creatinine $>2 \mathrm{mg}$ / $\mathrm{dL}$, aspartate aminotransferase (AST) or alanine aminotransferase (ALT) $>2.5 \times$ upper limit of normal (ULN), total bilirubin $>2.0 \times \mathrm{ULN})$. The purpose of this trial was to evaluate the efficacy of secondary prevention, not healing, and thus active ulcers and ulcer bleeding were not included. Further, the use of NSAID in patients with active ulcer is contraindicated and hence prohibited in Japan. Therefore, ethical committees do not allow the enrolment of such patients.

\section{Interventions}

During the double-blind and extension studies, all patients received a combination of one vonoprazan tablet $(10 \mathrm{mg}$ or $20 \mathrm{mg}$ ) or one placebo tablet and one lansoprazole $15 \mathrm{mg}$ capsule or one placebo capsule once daily orally after breakfast. The $15 \mathrm{mg}$ dose of lansoprazole was selected because that is the only dose approved for the prevention of NSAID-induced ulcer in Japan. Vonoprazan doses of $10 \mathrm{mg}$ and $20 \mathrm{mg}$ were selected 


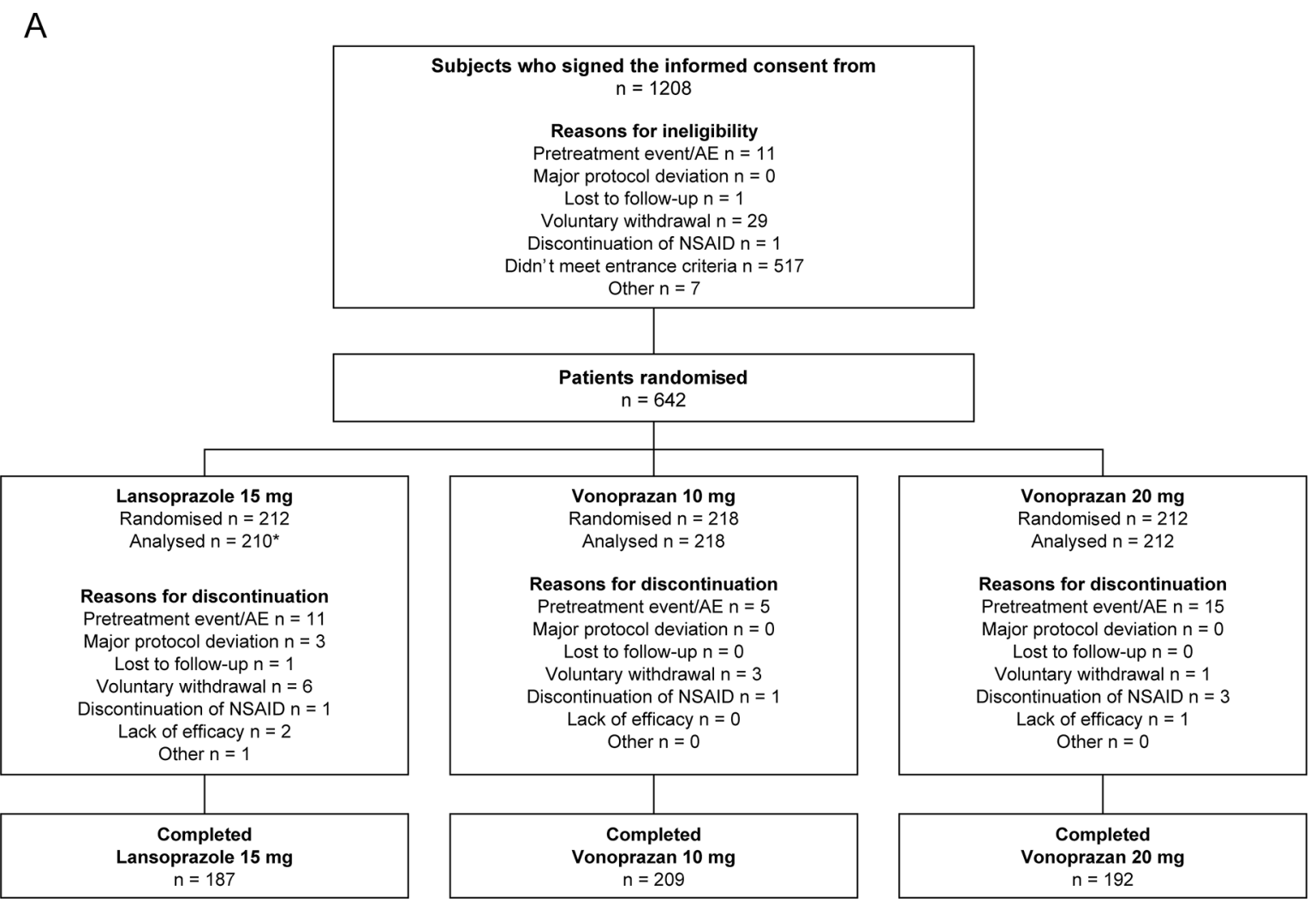

B

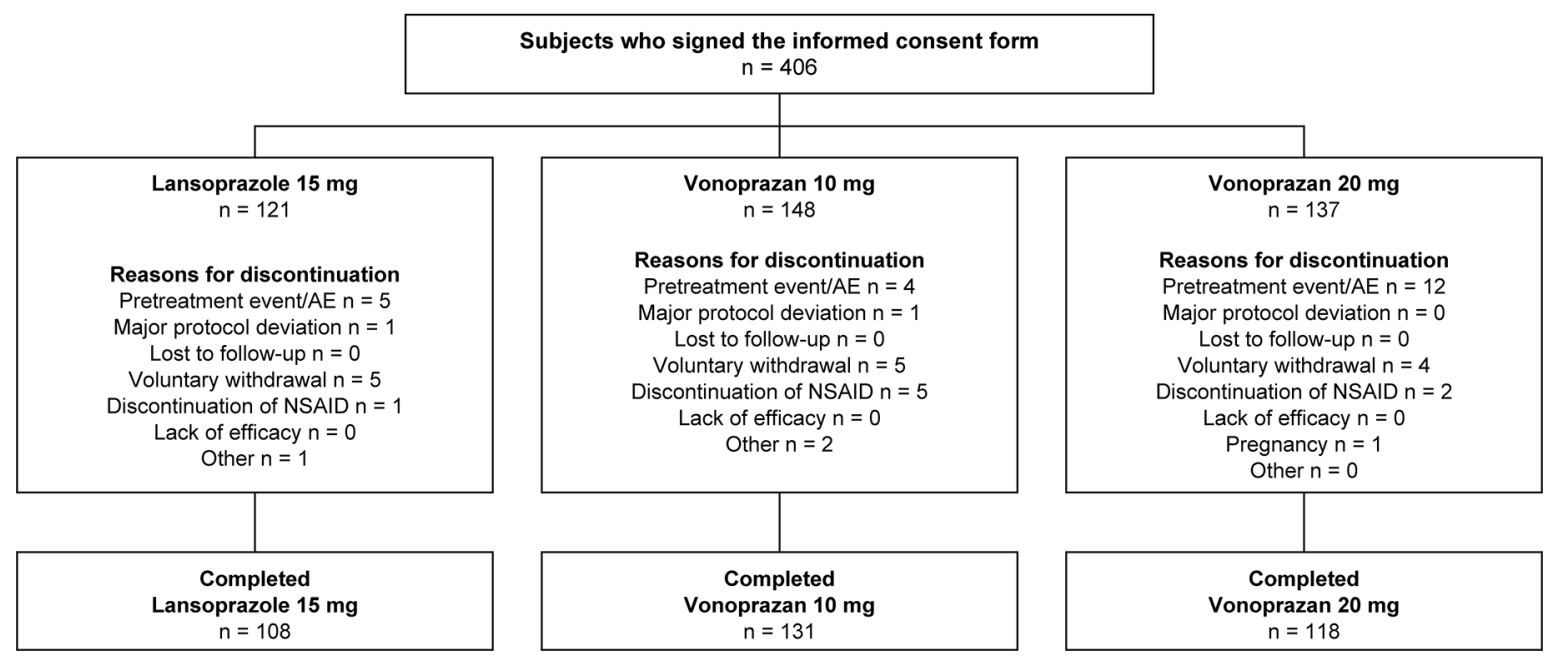

Figure 1 Patient disposition in the double-blind (A) and extension (B) studies.(A) Phase 3, multicenter, randomised, double-blind, parallel-group, non-inferiority study conducted to evaluate the non-inferiority of vonoprazan to lansoprazole in preventing occurrence of secondary ulcers in patients with a history of endoscopically confirmed gastric or duodenal ulcer (peptic ulcer) who require long-term NSAID therapy. (B) Phase 3, multicenter, single-blind, parallel-group extension study to evaluate the safety and ulcer recurrence during long-term drug exposure; subjects who completed the non-inferiority study were eligible for enrolment. One patient did not receive study medication. One patient was excluded due to protocol violations.

based on results from a dose-ranging study conducted in Japanese patients with erosive oesophagitis where the non-inferiority of vonoprazan (at doses of 5, 10, 20 and $40 \mathrm{mg}$ ) to lansoprazole $30 \mathrm{mg}$ was demonstrated. ${ }^{19}$ Furthermore, in previous clinical studies using PPIs, the investigated doses for prevention of ulcer recurrence were equivalent to or one-half of the therapeutic dose. $^{20}$

The administration of an NSAID had to have started before the initiation of the study treatment and followed the dosage and administration specified in the package insert of the NSAID. 
Patients on selective COX-2 inhibitors were also enrolled. The replacement of the NSAID with another NSAID and the change of its dosage were restricted. Aspirin at a dose of $1000 \mathrm{mg}$ or higher daily was considered as an NSAID.

\section{Randomisation and blinding}

An assignment manager (designated by the sponsor) generated a randomisation table. Patients were assigned to receive the next available study drug number allocated to each study site.

Bias was minimised by employing double-dummy blinding. The appearance of the vonoprazan $10 \mathrm{mg}, 20 \mathrm{mg}$ and placebo tablets and the appearance of the lansoprazole $15 \mathrm{mg}$ and placebo capsules were identical. Emergency key codes were stored by the Emergency Key Code Management Centre until the key code was broken in the event of an emergency or when the database was locked for all subjects.

\section{Outcomes}

The primary endpoint of the double-blind study was the proportion of patients with recurrent peptic ulcer during 24 weeks of treatment. Ulcer was defined as a mucosal defect with white coat of $3 \mathrm{~mm}$ or larger, measured using endoscopic forceps. Secondary endpoints were the proportions of patients with recurrent peptic ulcer up to 12 weeks, the proportion of patients with endoscopically proven bleeding in the stomach or duodenum evaluated according to the cases classified as I or II by modified Forrest classification $^{21}$ at week 12 and at week 24 and the time to event of peptic ulcer. Endoscopic findings (for ulcer scarring and recurrence) were investigated independently and blindly by the Central Evaluation Committee.

Safety was assessed on the basis of treatment-emergent AEs (TEAEs), laboratory test results, ECG, vital signs, serum gastrin and pepsinogen I or II levels. Serum gastrin (see table $1 \mathrm{~A}$ in the online supplementary file 2) and pepsinogen I and II levels (see tables $1 \mathrm{~B}$ and $1 \mathrm{C}$ in the online supplementary file 2 ) were measured, as it has been shown (phase 2 dose-ranging study) that they are significantly increased in patients with erosive oesophagitis receiving vonoprazan $\geq 10 \mathrm{mg} .{ }^{19}$ Before the study initiation, the special interest AEs (SIAEs) were liver function test abnormalities, defined as AST or ALT $>3 \times$ ULN or two consecutive measurements of total bilirubin $>2 \times$ ULN.

The primary endpoint of the extension study was the incidence of TEAEs. Safety was assessed in the same manner as in the double-blind study. The secondary efficacy endpoint was the proportion of patients with recurrent peptic ulcer. Secondary endpoints were the proportion of patients with bleeding in the stomach or duodenum and time to event of peptic ulcer.

\section{Statistical analysis}

Analyses were performed on combined data obtained from the double-blind and extension studies. All efficacy analyses were based on the full analysis set (FAS), defined as all randomised patients who received at least one dose of study medication. Demographics and other baseline characteristics were summarised using descriptive statistics (number of subjects, means and SD) for continuous variables and frequencies for categorical variables.

The primary objectives of the study were to demonstrate the non-inferiority of vonoprazan compared with lansoprazole and to support the new drug application of vonoprazan for the prevention of peptic ulcer recurrence during NSAID therapy in Japan. The non-inferiority of vonoprazan $10 \mathrm{mg}$ and $20 \mathrm{mg}$ to lansoprazole $15 \mathrm{mg}$ was tested using the Farrington and Manning test. $^{22}$ A planned sample size of 210 patients per treatment arm (630 patients in total) was based on historical recurrence rates in Japanese patients. ${ }^{10}$ This planned sample size was estimated to provide 154 subjects per treatment group after allowing for dropouts and at least $90 \%$ power to detect non-inferiority of vonoprazan to lansoprazole with a one-sided significance level of $2.5 \%$ and a non-inferiority margin of $8.3 \%$. The margin selected was half the value of the treatment difference observed between lansoprazole $15 \mathrm{mg}$ and gefarnate reported in a previous phase 3 study. $^{9}$ A closed testing procedure ${ }^{23}$ was used for multiplicity adjustment in the tests.

Recurrence rates of gastric or duodenal ulcer and the associated two-sided 95\% CIs were calculated for each visit by treatment group. Recurrence rate differences between each vonoprazan treatment group and the lansoprazole $15 \mathrm{mg}$ group were calculated for each visit using the combined data from the double-blind and extension studies. The cumulative incidences of peptic ulcer recurrence were calculated by the Kaplan-Meier method.

For the combined double-blind and extension studies, safety was assessed using the safety analysis set (defined as all patients who received study medication) and the frequency distribution of TEAEs was determined for each treatment group. Descriptive statistics were used to summarise continuous variables for observed values and changes from baseline at each visit. For categorical variables, shift tables indicated the number of patients in each category at baseline and each post-baseline visit.

Analyses were performed using SAS software (V.9.2; SAS Institute, Cary, North Carolina, USA).

\section{Ethics approval}

The studies were approved by the Institutional Review Board at each study site and were conducted in accordance with the International Conference on Harmonisation Guidelines for Good Clinical Practice, the principles of the World Medical Association Declaration of Helsinki and Japanese regulatory requirements. Patients provided written informed consent to participate. The studies were registered at ClinicalTrials.gov: NCT01452750 (double-blind study) and NCT01456260 (extension study).

\section{Role of the funding source}

The studies (NCT01452750 and NCT01456260) were funded in full by Takeda Pharmaceutical Company, Ltd. Takeda Pharmaceutical Company Ltd. contributed to the study design, research, interpretation of data, writing, reviewing and approving the publication.

\section{RESULTS}

\section{Subject disposition}

The double-blind study was conducted at 129 of 137 contracted sites in Japan from October 2011 to June 2013. Of the 1208 patients who provided informed consent, 642 were randomly assigned on a $1: 1: 1$ basis to receive vonoprazan $10 \mathrm{mg}$, vonoprazan $20 \mathrm{mg}$ or lansoprazole $15 \mathrm{mg}$; 641 patients were treated with the study drug and one patient was excluded because of a protocol violation; therefore, 640 patients comprised the FAS and safety analysis set (figure 1A). In all, 588 patients completed 24 weeks of treatment in the double-blind study. Main reasons for discontinuing study drug were AEs $(n=31)$, voluntary withdrawal $(n=10)$ and discontinuation of NSAID $(n=5)$.

The extension study with planned enrolments of 140 patients was conducted from April 2012 to December 2013 and involved 117 of the original sites. Of the patients who completed the first study, 406 patients gave consent to proceed to the extension phase 
Table 1 Demographic and baseline characteristics

\begin{tabular}{|c|c|c|c|}
\hline Characteristics & Lansoprazole 15 mg (n=212) & Vonoprazan $10 \mathrm{mg}(\mathrm{n}=218)$ & Vonoprazan $20 \mathrm{mg}(\mathrm{n}=212)$ \\
\hline Age, years, mean (SD) & $65.2(10.43)$ & $65.0(11.60)$ & $64.9(11.37)$ \\
\hline \multicolumn{4}{|l|}{ Gender, n (\%) } \\
\hline Male & $75(35.4)$ & $89(40.8)$ & $92(43.4)$ \\
\hline Female & $137(64.6)$ & $129(59.2)$ & $120(56.6)$ \\
\hline $\mathrm{BMI}, \mathrm{kg} / \mathrm{m}^{2}$, mean (SD) & $24.1(4.40)$ & $24.6(4.13)$ & $24.0(4.02)$ \\
\hline \multicolumn{4}{|l|}{ Underlying chronic disease, $\mathrm{n}(\%)$} \\
\hline Rheumatoid arthritis & $67(31.6)$ & $66(30.3)$ & 67 (31.6) \\
\hline Osteoarthritis & $75(35.4)$ & $92(42.2)$ & $65(30.7)$ \\
\hline Other & $128(60.4)$ & $131(60.1)$ & $130(61.3)$ \\
\hline \multicolumn{4}{|l|}{ NSAID used for long-term therapy, $n(\%)$} \\
\hline Selective COX-2 inhibitor & $51(24.1)$ & $65(29.8)$ & 71 (33.5) \\
\hline Other & $161(75.9)$ & $153(70.2)$ & $141(66.5)$ \\
\hline $\begin{array}{l}\text { Serum gastrin at screening, } \mathrm{pg} / \mathrm{mL} \text {, } \\
\text { mean (SD) }\end{array}$ & $270.5(340.04)$ & $309.2(377.76)$ & $320.1(609.75)$ \\
\hline
\end{tabular}

Serum gastrin at screening by RIA/PEG method. Reference value: $37-172 \mathrm{pg} / \mathrm{mL}$.

$\mathrm{BMI}$, body mass index; COX, cyclo-oxygenase; NSAID, non-steroidal anti-inflammatory drug.

Other NSAIDs used for long-term therapy included: loxoprofen sodium hydrate, meloxicam, diclofenac sodium, etc.

and 357 completed at least 28 weeks of treatment (figure 1B). Main reasons for failing to complete study treatment in the remaining 49 patients were AEs $(n=21)$, voluntary withdrawal $(n=14)$ or discontinuation of NSAID $(n=8)$.

Combined participation in the two studies ranged from 52 to 104 weeks.

\section{Baseline demographics}

Treatment groups were well matched at baseline for demographic and other clinical characteristics (table 1). The mean serum gastrin concentration at baseline was slightly higher in the vonoprazan $20 \mathrm{mg}$ group, but no clinically meaningful differences were noted among treatment groups for other parameters.

\section{Efficacy}

The proportion of patients in the FAS population with endoscopically confirmed recurrent peptic ulcers within 24 weeks was lower for the vonoprazan $10 \mathrm{mg}(3.3 \%)$ and $20 \mathrm{mg}(3.4 \%)$ groups compared with the lansoprazole $15 \mathrm{mg}$ group $(5.5 \%)$ (figure 2). The non-inferiority of vonoprazan $10 \mathrm{mg}$ and $20 \mathrm{mg}$ to lansoprazole was verified because the percentage difference between treatment groups was $<8.3 \%$ (percentage difference $-2.2 \%, 95 \%$ CI $-6.2 \%$ to $1.8 \%, \mathrm{p}<0.001 ;-2.1 \%, 95 \%$ CI $-6.1 \%$ to $2.0 \%, \mathrm{p}<0.001$, respectively).

Peptic ulcer recurred in the pyloric antrum (7), upper gastric body (3) and middle gastric body (1) for the lansoprazole group; pyloric antrum (4), upper gastric body (1), lower gastric body (1) and angular region (1) for the vonoprazan $10 \mathrm{mg}$ group and pyloric antrum (4), upper gastric body (1), angular region (1) and duodenal bulb (1) for the vonoprazan $20 \mathrm{mg}$ group. At each evaluation time point from weeks 12 to 104 , the proportion of patients with recurrent peptic ulcer was lower with vonoprazan $10 \mathrm{mg}$ and $20 \mathrm{mg}$ compared with lansoprazole $15 \mathrm{mg}$, but the differences between the treatment groups were not statistically significant (table 2). Similarly, the proportion of patients with bleeding in the stomach or duodenum was consistently lower with vonoprazan $10 \mathrm{mg}$ and $20 \mathrm{mg}$ compared with lansoprazole $15 \mathrm{mg}$ at all evaluation time points from weeks 12 to 104 , and once again the differences versus lansoprazole were not statistically significant (table 2).
The Kaplan-Meier cumulative incidence rates of peptic ulcer recurrence (figure 3A) and bleeding occurrence (figure $3 \mathrm{~B}$ ) were similar or lower in both vonoprazan groups compared with the lansoprazole $15 \mathrm{mg}$ group.

\section{Safety and tolerability}

Across both studies, the incidence of any TEAE was similar among treatment groups without any apparent dose-dependent increase between vonoprazan $10 \mathrm{mg}$ and $20 \mathrm{mg}$ (table 3 ). AEs for which a relationship with study medication could not be ruled out occurred in $<20 \%$ of patients in each treatment group. There were more AEs leading to study discontinuation reported in the vonoprazan $20 \mathrm{mg}$ group than the other groups. The vonoprazan $20 \mathrm{mg}$ group also recorded the highest number of serious AEs (36 events in 30 patients), but only two of these events (subcutaneous abscess and muscular weakness) were considered to be drug related.

The most common TEAE in all treatment groups was nasopharyngitis ( $~ 30 \%$ of patients), followed by fall and contusion (table 3). Most TEAEs were mild in intensity. Two drug-related serious AEs (aortic valve incompetence and putamen haemorrhage) were recorded in the vonoprazan $10 \mathrm{mg}$ group, two drug-related serious AEs (subcutaneous abscess and muscular weakness) were recorded in the vonoprazan $20 \mathrm{mg}$ group and one death (due to atherosclerosis) considered unrelated to treatment, occurred in the vonoprazan $20 \mathrm{mg}$ group during the double-blind study.

The number and incidence of SIAEs were low and similar between treatment groups (table 3). Drug-related SIAEs included abnormal hepatic function $(n=1)$ in the lansoprazole $15 \mathrm{mg}$ group and drug-induced liver injury $(n=1)$ and putamen haemorrhage $(n=1)$ in the vonoprazan $10 \mathrm{mg}$ group.

No clinically significant changes were observed pretreatment and post-treatment in any group for vital signs or for haematology tests, serum chemistry and urinalysis. Clinically significant ECG changes were reported in the vonoprazan $10 \mathrm{mg}$ group (week 24, $\mathrm{n}=1$; week 52, $\mathrm{n}=1$ ) and lansoprazole $15 \mathrm{mg}$ group (week 52, $\mathrm{n}=1$; week 64, $\mathrm{n}=1$ ).

Serum gastrin levels increased from baseline through to week 52 in all treatment groups (figure 4; see table $1 \mathrm{~A}$ in the online supplementary file 2). Serum gastrin levels were consistently 


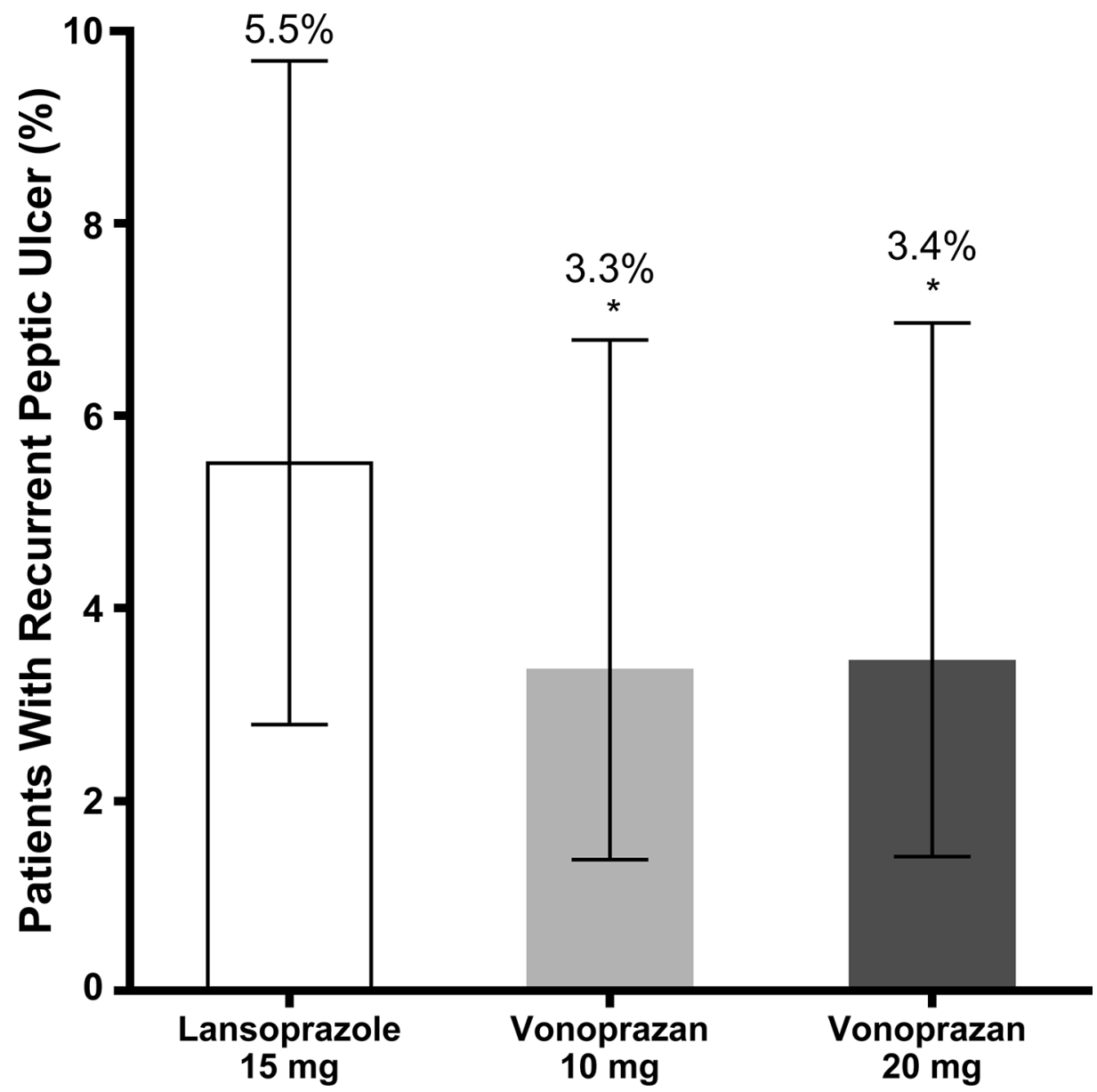

Figure 2 Peptic ulcer recurrence at week 24. The proportion of patients in the full analysis set population with endoscopically confirmed recurrent peptic ulcers within 24 weeks was lower for the vonoprazan $10 \mathrm{mg}$ and $20 \mathrm{mg}$ groups compared with the lansoprazole $15 \mathrm{mg}$ group. *Non-inferiority $\mathrm{p}<0.001$ versus lansoprazole $15 \mathrm{mg}$. Error bars indicate $95 \% \mathrm{Cls}$.

higher with vonoprazan than with lansoprazole, and the degree of increase with vonoprazan was dose dependent.

\section{DISCUSSION}

This is the first report to assess the efficacy and safety of vonoprazan for prevention of peptic ulcer recurrence in patients receiving long-term NSAID therapy. The results from these two phase 3 studies support the effectiveness of vonoprazan in preventing secondary ulcer recurrence at doses of $10 \mathrm{mg}$ and $20 \mathrm{mg}$ in Japanese patients receiving NSAIDs. Both doses of vonoprazan were non-inferior to lansoprazole $15 \mathrm{mg}$ and the ulcer-preventive effects were maintained for longer than 1 year

Table 2 Proportion of patients with recurrent peptic ulcer or bleeding (full analysis set)

\begin{tabular}{|c|c|c|c|c|c|c|c|}
\hline \multirow[b]{2}{*}{ Visit } & \multirow[b]{2}{*}{ Treatment } & \multicolumn{3}{|c|}{ Recurrent peptic ulcer } & \multicolumn{3}{|l|}{ Bleeding } \\
\hline & & Estimate $\%(\mathrm{n} / \mathrm{N})$ & Difference \% & $95 \% \mathrm{Cl}$ & Estimate $\%(\mathrm{n} / \mathrm{N})$ & Difference \% & $95 \% \mathrm{Cl}$ \\
\hline \multirow[t]{3}{*}{ Week 12} & Lansoprazole $15 \mathrm{mg}$ & $5.0(10 / 199)$ & & & $2.0(4 / 200)$ & & \\
\hline & Vonoprazan $10 \mathrm{mg}$ & $2.9(6 / 209)$ & -2.2 & -5.941 to 1.632 & $1.0(2 / 210)$ & -1.0 & -3.391 to1.296 \\
\hline & Vonoprazan $20 \mathrm{mg}$ & $3.0(6 / 203)$ & -2.1 & -5.896 to 1.757 & $1.0(2 / 199)$ & -1.0 & -3.379 to 1.389 \\
\hline \multirow[t]{3}{*}{ Week 24} & Lansoprazole $15 \mathrm{mg}$ & $5.5(11 / 199)$ & & & $2.0(4 / 200)$ & & \\
\hline & Vonoprazan $10 \mathrm{mg}$ & $3.3(7 / 209)$ & -2.2 & -6.182 to 1.826 & $1.4(3 / 210)$ & -0.6 & -3.090 to 1.94$]$ \\
\hline & Vonoprazan $20 \mathrm{mg}$ & $3.4(7 / 203)$ & -2.1 & -6.127 to 1.968 & $1.0(2 / 199)$ & -1.0 & -3.379 to 1.38$]$ \\
\hline \multirow[t]{3}{*}{ Week 52} & Lansoprazole $15 \mathrm{mg}$ & $7.0(14 / 199)$ & & & $2.0(4 / 200)$ & & \\
\hline & Vonoprazan $10 \mathrm{mg}$ & $3.8(8 / 209)$ & -3.2 & -7.611 to 1.196 & $1.4(3 / 210)$ & -0.6 & -3.090 to 1.947 \\
\hline & Vonoprazan $20 \mathrm{mg}$ & $5.4(11 / 203)$ & -1.6 & -6.341 to 3.108 & $1.5(3 / 199)$ & -0.5 & -3.068 to 2.083 \\
\hline \multirow[t]{3}{*}{ Week 76} & Lansoprazole $15 \mathrm{mg}$ & $7.5(15 / 199)$ & & & $2.0(4 / 200)$ & & \\
\hline & Vonoprazan $10 \mathrm{mg}$ & $3.8(8 / 209)$ & -3.7 & -8.207 to 0.787 & $1.4(3 / 210)$ & -0.6 & -3.090 to 1.947 \\
\hline & Vonoprazan $20 \mathrm{mg}$ & $5.9(12 / 203)$ & -1.6 & -6.523 to 3.271 & $1.5(3 / 199)$ & -0.5 & -3.068 to 2.083 \\
\hline \multirow[t]{3}{*}{ Week 104} & Lansoprazole $15 \mathrm{mg}$ & $7.5(15 / 199)$ & & & $2.0(4 / 200)$ & & \\
\hline & Vonoprazan $10 \mathrm{mg}$ & $3.8(8 / 209)$ & -3.7 & 8.207 to 0.787 & $1.4(3 / 210)$ & -0.6 & -3.090 to 1.947 \\
\hline & Vonoprazan $20 \mathrm{mg}$ & $5.9(12 / 203)$ & -1.6 & 6.523 to 3.271 & $1.5(3 / 199)$ & -0.5 & -3.068 to 2.083 \\
\hline
\end{tabular}



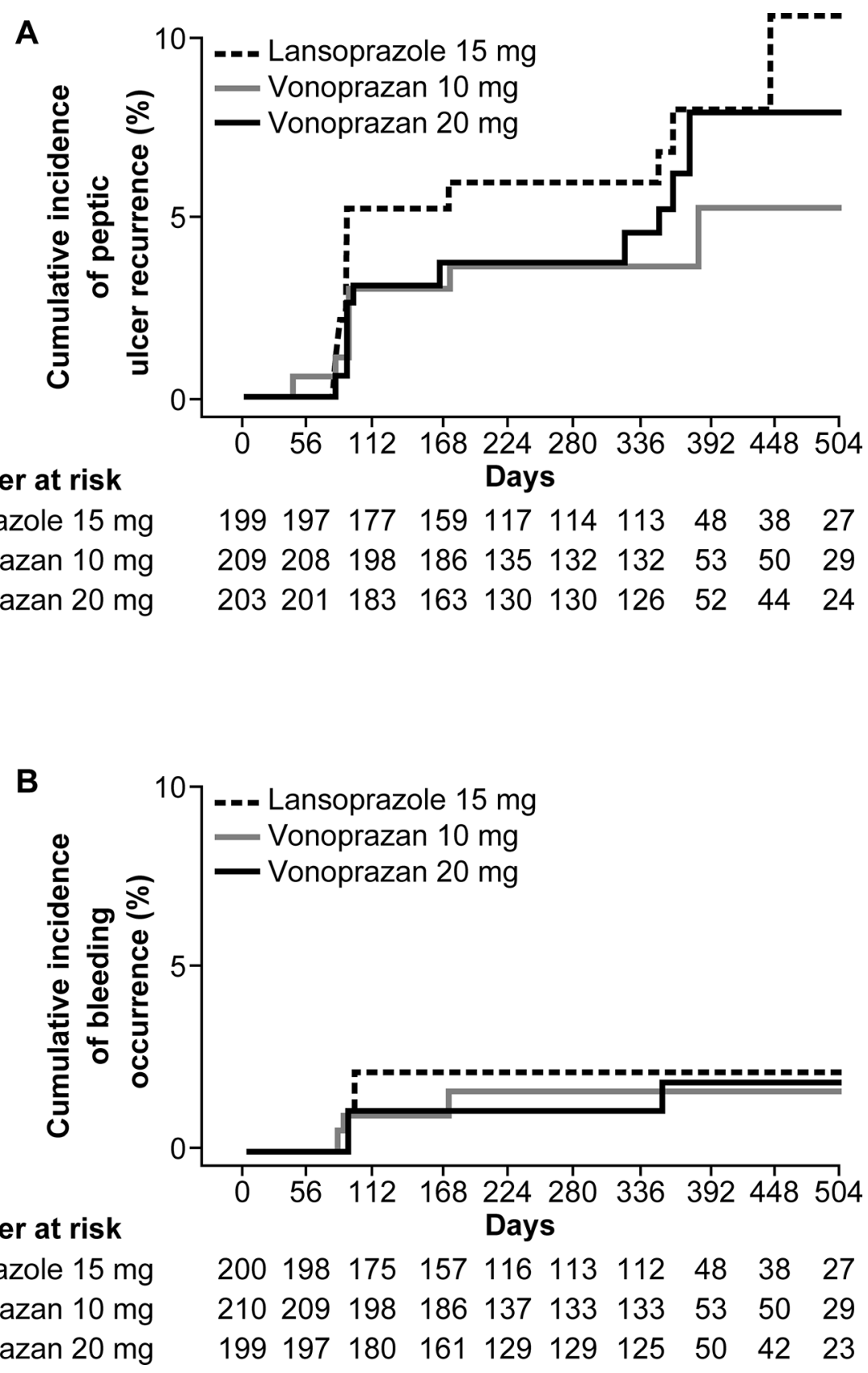

Figure 3 Kaplan-Meier cumulative incidence of peptic ulcer recurrence $(A)$ and bleeding (B)The cumulative incidence rates of peptic ulcer recurrence and bleeding occurrence were similar or lower in both vonoprazan groups compared with the lansoprazole group.

(as shown in table 2). The ulcer-preventive effects of lansoprazole (active control) were consistent with previously published studies. ${ }^{9}{ }^{24}$ The studies also support the safety of long-term use of vonoprazan, which was similar to that of lansoprazole $15 \mathrm{mg}$. Importantly, no unexpected safety concerns were identified during the longer than 1 year exposure to vonoprazan.

Japanese guidelines recommend concomitant use of PPIs or prostaglandin analogues with NSAIDs for the prevention of NSAID-induced ulcers. ${ }^{5}$ Few studies have directly compared these agents; however, a meta-analysis revealed that while PPIs, double-dose H2RAs and prostaglandin analogues are effective in secondary ulcer prevention, these agents may not be completely effective. ${ }^{25}$ Therefore, PPIs with higher efficacy and fewer AEs may be considered the best choice for prevention of secondary ulcers. ${ }^{25}$ The results of the current studies are consistent with those of previous studies that investigated the effectiveness of PPIs in secondary ulcer prevention in Japanese patients. ${ }^{9} 2627$ Furthermore, they demonstrate that vonoprazan is as effective as lansoprazole. The proportion of patients with recurrent ulcer and bleeding was lower with vonoprazan compared with lansoprazole, though the differences were not statistically significant. Therefore, vonoprazan has the potential to be a clinically useful alternative to PPIs, especially for patients with high risk factors.

As not all patients receiving NSAIDs develop peptic ulcers during treatment, the study specifically enrolled subjects with risk factors, namely, a history of endoscopically confirmed peptic ulcer and the requirement for continuous long-term NSAID therapy (including a selective COX-2 inhibitor) for pain management. The numerically greater preventive effect of vonoprazan $10 \mathrm{mg}$ and $20 \mathrm{mg}$ compared with lansoprazole $15 \mathrm{mg}$ on ulcer recurrence was evident within 12 weeks of treatment and 
Table 3 Summary of TEAE occurring in $\geq 5 \%$ of patients across the non-inferiority and extension studies (safety analysis set)

\begin{tabular}{|c|c|c|c|c|c|c|c|}
\hline \multirow[b]{2}{*}{ Event } & \multicolumn{2}{|c|}{$\begin{array}{l}\text { Lansoprazole } 15 \mathrm{mg} \\
(\mathrm{n}=210)\end{array}$} & \multicolumn{2}{|c|}{ Vonoprazan $10 \mathrm{mg}(\mathrm{n}=218)$} & \multicolumn{2}{|c|}{ Vonoprazan $20 \mathrm{mg}(\mathrm{n}=212)$} & \multirow[b]{2}{*}{ Statistical test } \\
\hline & Events, $\mathbf{n}$ & Patients, n (\%) & Events, $\mathbf{n}$ & Patients, n (\%) & Events, $\mathbf{n}$ & Patients, n (\%) & \\
\hline Summary of AEs & & & & & & & $\mathrm{X}^{2}$ test \\
\hline Any $\mathrm{AE}$ & 634 & $\begin{array}{l}185 \\
(88.1)\end{array}$ & 758 & $\begin{array}{l}184 \\
(84.4)\end{array}$ & 731 & $\begin{array}{l}175 \\
(82.5)\end{array}$ & $p=0.2673$ \\
\hline Drug-related AE & 44 & $\begin{array}{l}40 \\
(19.0)\end{array}$ & 52 & $\begin{array}{l}38 \\
(17.4)\end{array}$ & 51 & $\begin{array}{l}37 \\
(17.5)\end{array}$ & $\mathrm{p}=0.8839$ \\
\hline Leading to study discontinuation & 17 & $\begin{array}{l}16 \\
(7.6)\end{array}$ & 9 & $\begin{array}{l}9 \\
(4.1)\end{array}$ & 32 & $\begin{array}{l}27 \\
(12.7)\end{array}$ & $p=0.0046$ \\
\hline Any serious $\mathrm{AE}^{*}$ & 20 & $\begin{array}{l}18 \\
(8.6)\end{array}$ & 22 & $\begin{array}{l}18 \\
(8.3)\end{array}$ & 36 & $\begin{array}{l}30 \\
(14.2)\end{array}$ & $p=0.0796$ \\
\hline Serious drug-related AE $\dagger$ & 0 & $\begin{array}{l}0 \\
(0)\end{array}$ & 2 & $\begin{array}{l}2 \\
(0.9)\end{array}$ & 2 & $\begin{array}{l}2 \\
(0.9)\end{array}$ & $p=0.3740$ \\
\hline Special interest AE $\ddagger$ & 2 & $\begin{array}{l}2 \\
(1.0)\end{array}$ & 5 & $\begin{array}{l}5 \\
(2.3)\end{array}$ & 4 & $\begin{array}{l}3 \\
(1.4)\end{array}$ & $p=0.5232$ \\
\hline Drug-related special interest AE & 1 & $\begin{array}{l}1 \\
(0.5)\end{array}$ & 2 & $\begin{array}{l}2 \\
(0.9)\end{array}$ & 0 & $\begin{array}{l}0 \\
(0)\end{array}$ & $p=0.3792$ \\
\hline \multicolumn{8}{|c|}{ TEAEs reported in $\geq 5 \%$ of patients in any treatment group by preferred term, $n(\%)$} \\
\hline Nasopharyngitis & $61(29.0)$ & & $70(32.1)$ & & $59(27.8)$ & & \\
\hline Fall & $18(8.6)$ & & $22(10.1)$ & & $18(8.5)$ & & \\
\hline Contusion & $20(9.5)$ & & $17(7.8)$ & & $14(6.6)$ & & \\
\hline Diarrhoea & $14(6.7)$ & & $11(5.0)$ & & $15(7.1)$ & & \\
\hline Upper respiratory tract inflammation & $7(3.3)$ & & $12(5.5)$ & & $14(6.6)$ & & \\
\hline Seasonal allergy & $8(3.8)$ & & $8(3.7)$ & & $15(7.1)$ & & \\
\hline Eczema & $12(5.7)$ & & $10(4.6)$ & & $8(3.8)$ & & \\
\hline Elevated blood creatine phosphokinase & $11(5.2)$ & & $9(4.1)$ & & $7(3.3)$ & & \\
\hline Constipation & $5(2.4)$ & & $15(6.9)$ & & $7(3.3)$ & & \\
\hline Back pain & $6(2.9)$ & & $7(3.2)$ & & $13(6.1)$ & & \\
\hline Contact dermatitis & $6(2.9)$ & & $8(3.7)$ & & $12(5.7)$ & & \\
\hline Stomatitis & $7(3.3)$ & & $11(5.0)$ & & $4(1.9)$ & & \\
\hline Dental caries & $11(5.2)$ & & $6(2.8)$ & & $4(1.9)$ & & \\
\hline
\end{tabular}

* Serious $A E$

†Serious drug-related $A E$ : putamen haemorrhage.

$¥$ Special interest $\mathrm{AE}$ : liver function test abnormal.

$A E$, adverse event; $T E A E$, treatment-emergent $A E$.

was maintained up to 2 years. Interestingly, the ulcer recurrence rate within 24 weeks observed with lansoprazole $15 \mathrm{mg}$ in the present study $(5.5 \%)$ was similar to that reported in a phase 3 study of lansoprazole $15 \mathrm{mg}$ conducted in a similar population also receiving long-term NSAID therapy (5.9\%). ${ }^{10}$ Despite the small number of patients with bleeding in the stomach and duodenum throughout the course of the study, the proportion of patients with bleeding was consistently lower with vonoprazan $10 \mathrm{mg}$ or $20 \mathrm{mg}$ compared with lansoprazole $15 \mathrm{mg}$ from week 12 through to week 104 .

Vonoprazan was well tolerated with no apparent dose-dependent increase in the incidence of TEAEs. The safety profiles of the $10 \mathrm{mg}$ and $20 \mathrm{mg}$ doses were similar to that of lansoprazole $15 \mathrm{mg}$ over 104 weeks' treatment. Although a greater number of patients in the vonoprazan $20 \mathrm{mg}$ group discontinued treatment due to TEAEs, there was no clear pattern either by event or system organ class to account for this observation. Seven patients treated with vonoprazan $20 \mathrm{mg}$ discontinued treatment because of musculoskeletal disorders (compared with one patient treated with lansoprazole $15 \mathrm{mg}$ and no patients treated with vonoprazan $10 \mathrm{mg}$ ), but the events were likely related to the underlying condition. Nevertheless, this finding may be worthy of further investigation. The death in the vonoprazan $20 \mathrm{mg}$ group was attributed to atherosclerosis and was considered unrelated to treatment.
Mean serum gastrin concentrations were consistently higher from week 4 onwards in both vonoprazan treatment groups compared with the lansoprazole treatment group, and the increases were dose dependent. However, the changes were not considered clinically meaningful and no patients withdrew from either treatment group. Levels tended to plateau after week 4 and then increased gradually throughout the remainder of the study. The increase in serum gastrin concentration is believed to be a consequence of the potent gastric acid antisecretory effect of vonoprazan.

The strengths of the study include the use of lansoprazole as an active comparator versus two doses of vonoprazan, the doubleblind study design with the large sample size and the parallel-group extension study design with long-term exposure. Additionally, the double-blind study included a conservative and reliable active control rate of $5.5 \%$, long duration of follow-up and robust analytical and statistical methods. However, the variable duration of drug exposure in the extension study may limit our conclusions.

In conclusion, vonoprazan $10 \mathrm{mg}$ and $20 \mathrm{mg}$ were effective and well tolerated for prevention of peptic ulcer recurrence during NSAID therapy in at-risk Japanese patients and the preventive effect was maintained with long-term use. The safety profile of vonoprazan $10 \mathrm{mg}$ and $20 \mathrm{mg}$ during long-term use was similar to that of lansoprazole $15 \mathrm{mg}$ and no new safety issues were identified. The lower dose of $10 \mathrm{mg}$ has been approved in Japan 

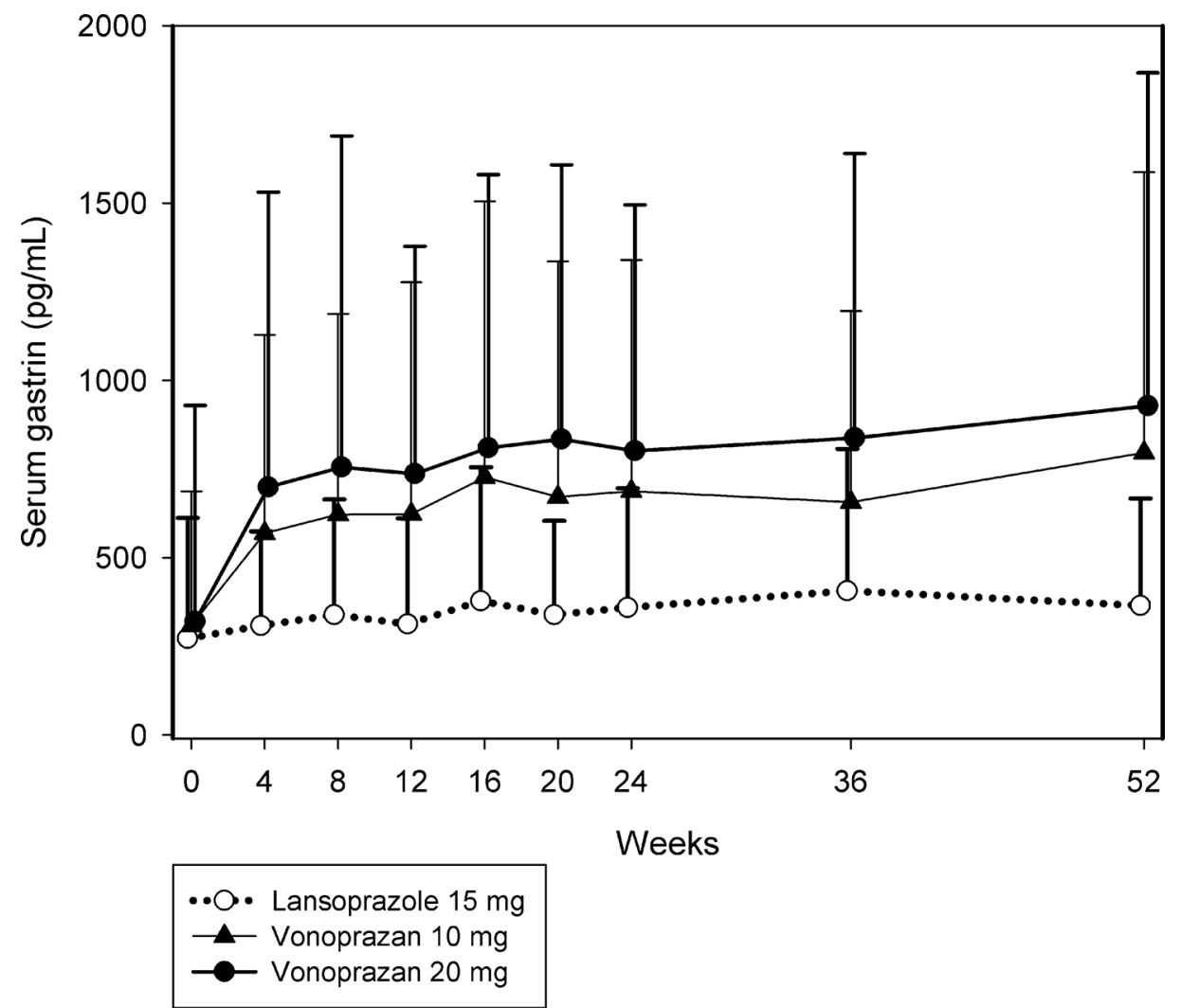

Figure 4 Mean serum gastrin concentrations. Error bars indicate SD. Additional data are provided in table 1A in the online supplementary file 2.

as the clinical daily dose of vonoprazan for prevention of recurrent peptic ulcers during long-term NSAID therapy.

Acknowledgements The authors would like to thank all contributing members listed in Appendix Table 2 and the sponsor.

Contributors YM and KA were consultants for the clinical endpoint committee members for this study. SS was the medical adviser and TK was the medical expert for the study. KO and AN were responsible for clinical/scientific aspects of the study. NF was responsible for statistical analysis. Writing assistance was provided by content Ed Net and by Tania Dickson, PhD and Rebecca Lew, PhD, CMPP of ProScribe, Envision Pharma Group. KS was the coordinating investigator of this study.

Funding The study and writing assistance were funded by Takeda pharmaceutical company.

Competing interests YM has served as a consultant for, received grant and honorarium from Takeda Pharmaceutical Company. KO, NF and AN are employees of Takeda Pharmaceutical Company. SS has served as a consultant for and received a grant, honorarium and travel fee from Takeda Pharmaceutical Company. TK, KA and KS have served as a consultant and received a grant and honorarium from Takeda Pharmaceutical Company.

Patient consent Obtained.

Ethics approval This study is conducted in accordance with the standards of good clinical practice and incompliance with the declaration of Helsinki 2013 and local regulations, and has been submitted and approved by the institutional review boards of the study facilities.

Provenance and peer review Not commissioned; internally peer reviewed.

Open Access This is an Open Access article distributed in accordance with the Creative Commons Attribution Non Commercial (CC BY-NC 4.0) license, which permits others to distribute, remix, adapt, build upon this work non-commercially, and license their derivative works on different terms, provided the original work is properly cited and the use is non-commercial. See: http://creativecommons.org/ licenses/by-nc/4.0/

(C) Article author(s) (or their employer(s) unless otherwise stated in the text of the article) 2018. All rights reserved. No commercial use is permitted unless otherwise expressly granted.

\section{REFERENCES}

$1 \mathrm{McCarberg} B \mathrm{~B}$, Cryer B. Evolving therapeutic strategies to improve nonsteroidal antiinflammatory drug safety. Am J Ther 2015;22:e167-e178.

2 Shiokawa Y, Nobunaga M, Saito T, et al. [Epidemiology study on upper gastrointestinal lesions induced by non-steroidal anti-inflammatory drugs]. Ryumachi 1991;31:96-111.

3 Armstrong CP, Blower AL. Non-steroidal anti-inflammatory drugs and life threatening complications of peptic ulceration. Gut 1987;28:527-32.

4 Larkai EN, Smith JL, Lidsky MD, et al. Gastroduodenal mucosa and dyspeptic symptoms in arthritic patients during chronic nonsteroidal anti-inflammatory drug use. Am J Gastroenterol 1987:82:1153-8.

5 Satoh K, Yoshino J, Akamatsu T, et al. Evidence-based clinical practice guidelines for peptic ulcer disease 2015. J Gastroenterol 2016:51:177-94.

6 Furner SE, Hootman JM, Helmick CG, et al. Health-related quality of life of US adults with arthritis: analysis of data from the behavioral risk factor surveillance system, 2003, 2005, and 2007. Arthritis Care Res 2011;63:788-99.

7 Gargallo CJ, Sostres C, Lanas A. Prevention and treatment of NSAID gastropathy. Curr Treat Options Gastroenterol 2014;12:398-413.

8 Rostom A, Muir K, Dube C, et al. Prevention of NSAID-related upper gastrointestinal toxicity: a meta-analysis of traditional NSAIDs with gastroprotection and COX-2 inhibitors. Drug Healthc Patient Saf 2009;1:47-71.

9 Sugano K, Kontani T, Katsuo S, et al. Lansoprazole for secondary prevention of gastric or duodenal ulcers associated with long-term non-steroidal antiinflammatory drug (NSAID) therapy: results of a prospective, multicenter, double-blind, randomized, double-dummy, active-controlled trial. J Gastroenterol 2012:47:540-52.

10 Hori Y, Imanishi A, Matsukawa J, et al. 1-[5-(2-Fluorophenyl)-1-(pyridin-3-ylsulfonyl)$1 \mathrm{H}$-pyrrol-3-yl]-N-methylmethanamine monofumarate (TAK-438), a novel and potent potassium-competitive acid blocker for the treatment of acid-related diseases. J Pharmacol Exp Ther 2010;335:231-8.

11 Chan FK, Wong VW, Suen BY, et al. Combination of a cyclo-oxygenase-2inhibitor for prevention of recurrent ulcer bleeding in patients at very high risk: a double-blind randomised trial. Lancet 2007;369:1621-6.

12 Matsukawa J, Kogame A, Tagawa Y, et al. Localization of a novel potassium competitive acid blocker, vonoprazan, in the rat gastric mucosa: a radiographic study. Dig Dis Sci 2016;61:1888-94.

13 Hori Y, Matsukawa J, Takeuchi T, et al. A study comparing the antisecretory effect of TAK-438, a novel potassium-competitive acid blocker, with lansoprazole in animals. J Pharmacol Exp Ther 2011;337:797-804.

14 Shin JM, Inatomi N, Munson K, et al. Characterization of a novel potassiumcompetitive acid blocker of the gastric H,K-ATPase, 1-[5-(2-fluorophenyl)-1-(pyridin- 
3-ylsulfonyl)-1H-pyrrol-3-yll-N-methylmethanamine monofumarate (TAK-438). J Pharmacol Exp Ther 2011;339:412-20.

15 Williams MP, Sercombe J, Hamilton MI, et al. A placebo-controlled trial to assess the effects of 8 days of dosing with rabeprazole versus omeprazole on 24-h intragastric acidity and plasma gastrin concentrations in young healthy male subjects. Aliment Pharmacol Ther 1998:12:1079-89.

16 Sakurai Y, Mori Y, Okamoto H, et al. Acid-inhibitory effects of vonoprazan $20 \mathrm{mg}$ compared with esomeprazole $20 \mathrm{mg}$ or rabeprazole $10 \mathrm{mg}$ in healthy adult male subjects--a randomised open-label cross-over study. Aliment Pharmacol Ther 2015:42:719-30

17 Sakurai Y, Shiino M, Horii S, et al. Pharmacokinetic drug-drug interactions between vonoprazan and low-dose aspirin or nonsteroidal anti-inflammatory drugs: A phase 2, open-label, study in healthy Japanese men. Clin Drug Investig 2017;37:39-49.

18 Miwa H, Uedo N, Watari J, et al. Randomised clinical trial: efficacy and safety of vonoprazan vs. lansoprazole in patients with gastric or duodenal ulcers - results from two phase 3, non-inferiority randomised controlled trials. Aliment Pharmacol Ther 2017:45:240-52.

19 Ashida K, Sakurai Y, Nishimura A, et al. Randomised clinical trial: a dose-ranging study of vonoprazan, a novel potassium-competitive acid blocker, vs. lansoprazole for the treatment of erosive oesophagitis. Aliment Pharmacol Ther 2015;42:685-95.

20 Graham DY, Agrawal NM, Campbell DR, et al. Ulcer prevention in long-term users of nonsteroidal anti-inflammatory drugs: results of a double-blind, randomized, multicenter, active- and placebo-controlled study of misoprostol vs lansoprazole. Arch Intern Med 2002;162:169-75.

21 Kohler B, Riemann JF. Upper GI-bleeding - value and consequences of emergency endoscopy and endoscopic treatment. Hepatogastroenterology 1991;38:198-200.

22 Farrington CP, Manning G. Test statistics and sample size formulae for comparative binomial trials with null hypothesis of non-zero risk difference or non-unity relative risk. Stat Med 1990;9:1447-54.

23 Marcus R, Eric P, Gabriel KR. On closed testing procedures with special reference to ordered analysis of variance. Biometrika 1976;63:655-60.

24 Sugano K, Matsumoto Y, Itabashi T, et al. Lansoprazole for secondary prevention of gastric or duodenal ulcers associated with long-term low-dose aspirin therapy: results of a prospective, multicenter, double-blind, randomized, double-dummy, activecontrolled trial. J Gastroentero/ 2011:46:724-35.

25 Goldstein JL, Huang B, Amer F, et al. Ulcer recurrence in high-risk patients receiving nonsteroidalanti-inflammatory drugs plus low-dose aspirin: results of a post $\mathrm{HOC}$ subanalysis. Clin Ther 2004:26:1637-43.

26 Sugano K, Kinoshita Y, Miwa H, et al. Safety and efficacy of long-term esomeprazole $20 \mathrm{mg}$ in Japanese patients with a history of peptic ulcer receiving daily non-steroidal anti-inflammatory drugs. BMC Gastroenterol 2013;13:54.

27 Sugano K, Kinoshita Y, Miwa H, et al. Randomised clinical trial: esomeprazole for the prevention of nonsteroidal anti-inflammatory drug-related peptic ulcers in Japanese patients. Aliment Pharmacol Ther 2012;36:115-25. 